\title{
How to diagnose equal opportunities between women and men in organizations
}

\author{
Amaia Lusa, Carme Martínez, Maria Dolors Calvet, Olga Pons, Marta Tura \\ Universitat Politécnica de Catalunya (SPAIN) \\ amaia.lusa@upc.edu;mcarme.martinez@upc.edu;m.dolors.calvet@upc.edu; olga.pons@upc.edu; \\ marta.tura@upc.edu
}

Received March 2009

Accepted September 2009

\begin{abstract}
Gender equality is now a matter that concerns all European countries. Despite the great effort made by governments and the progress of laws, gender discrimination still exists in family, social, cultural, political and economic spheres. Even today, it is rare to find women at the top level in companies. The path to equal opportunities is long and the only way to improve the situation is by means of appropriate equal opportunities plans. An essential part of the process of designing and implementing such action plans involves diagnosing the situation in a company. In this paper, an innovative indicator model is proposed. A review of numerous international private and public equal opportunities plans led to the design of a model to carry out a diagnose to identify all areas that could be corrected or improved by implementing specific measures, leading the company to deliver real equal opportunities policies. The indicator model is designed for the present historical context, though it is flexible enough to be adapted to each age and situation. The indicator model, which is original, will help companies carrying out one of the most important and essential parts of the process of designing and implementing and equal opportunities plan. Moreover, taking the indicator model companies ensure that all the relevant features are covered.
\end{abstract}

Keywords: equal opportunities, gender mainstreaming, diagnose, management, human resources 


\section{Introduction}

In developed countries, all kinds of discrimination are now banned by law. Of course, nobody questions women's ability to occupy the same positions as men. However, theory and reality differ. Women find that obstacles prevent them from developing their career and having the same opportunities as men (Kirton \& Greene, 2005; Knights \& Richards, 2003).

The way to gender equality is long (Rubery, Grimshaw, Fagan, Figueiredo, \& Smith, 2003). Despite the great advances in society's awareness and in the development of laws and regulations, barriers and stereotypes still exist that prevent women from playing a full role in political, social, cultural and labour spheres.

Women do not have equal opportunities in the labour market. There is strong evidence (European Commission, 2006a; Gonäs, 2004) that women are underrepresented in some sectors, studies, professions and top level positions in companies.

Gender discrimination is often very difficult to detect. This can be due to the lack of sensitivity of the person who is doing the discriminating and the resignation of the person who is being discriminated against. On other occasions, it is due to the fact that discrimination is subtly hidden in processes that are apparently neutral but that affect a group detrimentally. Note that in such situations, the person who is being discriminated against is probably not even aware of it.

As a result of thousands of years of gender discrimination, women are in a less favourable position than men. The main obstacles to equal opportunities at work are the difference in the roles the society imposes on each gender; the responsibility for children and the house which mainly falls on women; and the interruption of women's careers due to reproduction at certain times of their lives.

We can compare the situation to a race in which men have a headstart of several metres. This makes it very difficult for a woman to reach a man's position, even if she runs faster than he does. Hence, today a lack of gender discrimination is neither a sufficient condition nor a guarantee of real equal opportunities between women and men. 
Only the development of an equal opportunities policy and the implementation of an action plan will enable a company to detect discrimination and disadvantage and to eliminate all barriers and stereotypes (Eurofund, 2002). Like any managerial strategy, an equal opportunities plan has to be designed ad hoc according to the company's specific characteristics and to its starting point. Thus, an essential factor in the process of developing a policy and action plan is an assessment or diagnosis of the equal opportunities situation. Such an assessment allows the company to discover all the factors that could be improved or corrected. Through this process, the company can begin to deliver real equal opportunities.

In contrast to what is often believed, assessing equal opportunities between men and women is not just a matter of counting how many women there are in different positions and departments or at high levels of responsibility (European Commission, 2006b). Of course, it is useful to do this, because it gives an overall idea of the situation. However, a complete diagnosis must cover all relevant aspects of a company: its overall policy, internal processes, human resources management policies, internal and external communication, labour conditions, etc. (Rees, 1998; Rubery, 2002).

In this paper, we propose an innovative indicator model that goes beyond the collection of data by gender to provide a methodology for collecting and analyzing data from a gender perspective. This methodology allows us to analyze and report on policies to promote equal opportunities that are taking place all the time.

This is a method for assessing all the aspects of a company whose correction or improvement could help it to deliver equal opportunities for women and men. First section proposes a fast method for obtaining an initial view of the situation; second, an indicator model that could be used to carry out a complete diagnosis is proposed; finally, some conclusions are presented.

\section{Getting started: a fast diagnose}

One of the most obvious consequences of a lack of equal opportunities practices and processes is the absence of women in higher categories and with high levels of responsibility. Hence, in this initial first diagnosis we propose analyzing the proportion of women with high levels of responsibility and in the different categories. Note that to ensure a critical mass in a decision-making body, at least 
$40 \%$ (approximately) of each sex must be represented. Hence, when a category, department, level of responsibility, etc. is well-balanced, neither women nor men should represent more than $60 \%$ or less than $40 \%$.

This analysis should be carried out on both general and detailed levels (i.e. by units, departments, etc.).

Different types of data or information can be used to give a fairly reliable idea of the representation of women in a company. Such data includes:

- The percentage of women with high levels of responsibility (supervisors, managers, directors, etc.).

- The percentage of women in the different categories. This should take into account the evolution from lower to higher categories. It is very useful to plot these data ( $\%$ of women and \% of men, by category). Figures 1, 2 and 3 represent three different examples.

o Example 1 shows a company in a sector in which there are a high number of women (e.g., administration, services, etc.) but in which there is strong vertical segregation. In other words, opportunities for promotion and career development are not equal. In the end, mainly men occupy the higher categories (due to internal promotion or because they directly access these categories).

o Example 2 shows a company in a feminized sector (i.e., a sector in which the percentage of women is very high). In this example, the percentage of women is similar in all the categories and there are equal promotion opportunities. Note that the opposite situation would be a company with few women but with the same percentages in all categories (i.e., no gender discrimination in promotion).

- Example 3 reflects an ideal situation in which the percentages of women and men are well-balanced in all categories. There are equal opportunities in both recruitment and promotion. 


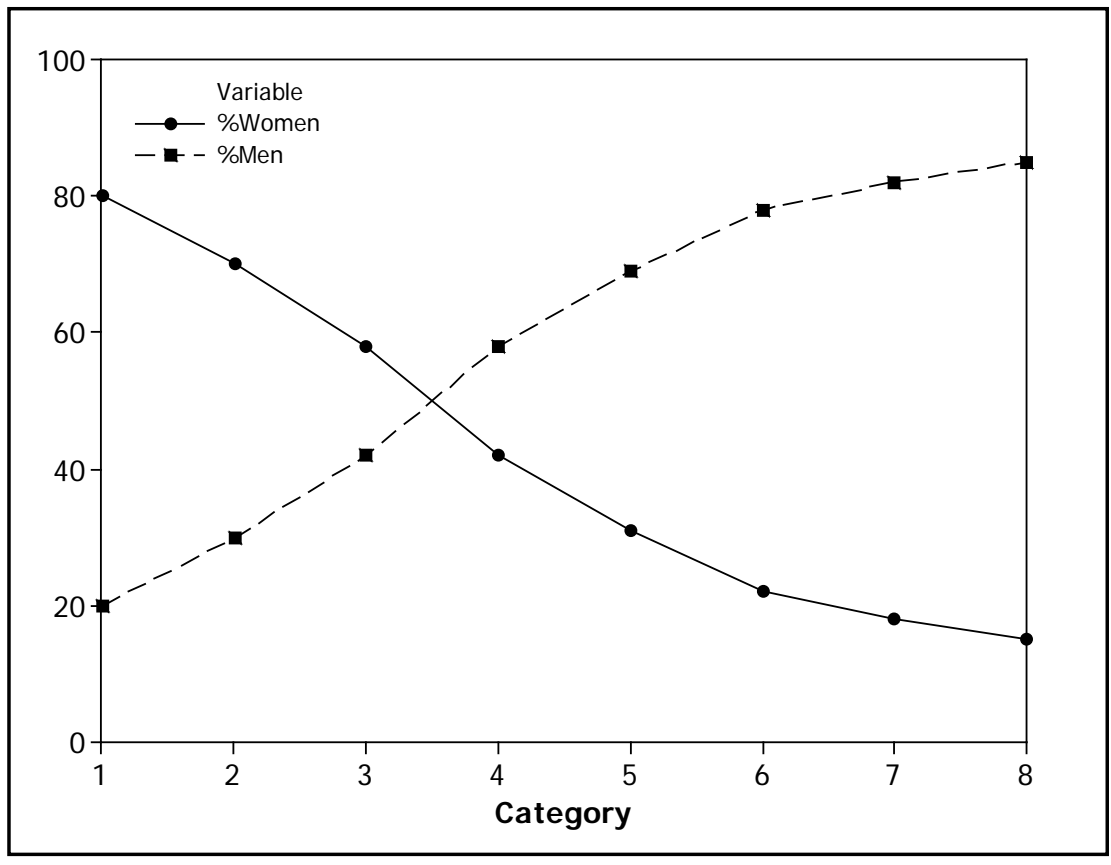

Figure 1. "Percentage of women and men by category. Example 1". Source: Own contribution

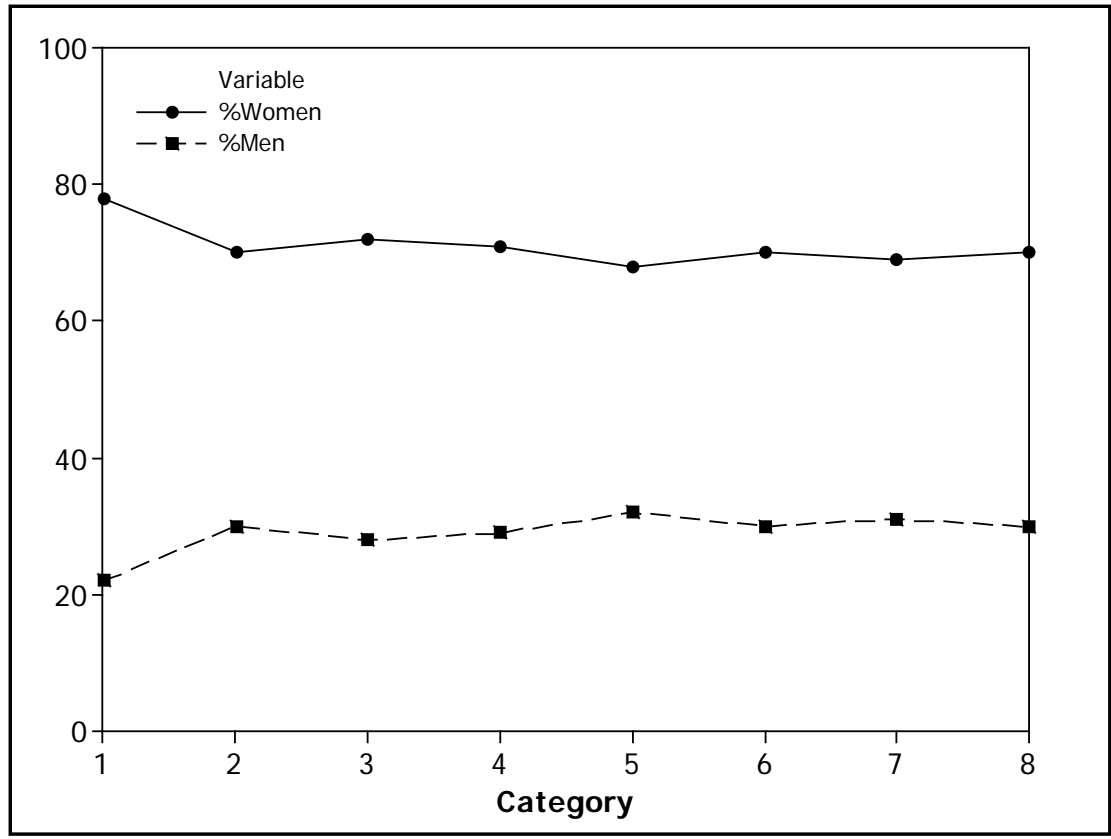

Figure 2. "Percentage of women and men by category. Example 2". Source: Own contribution 


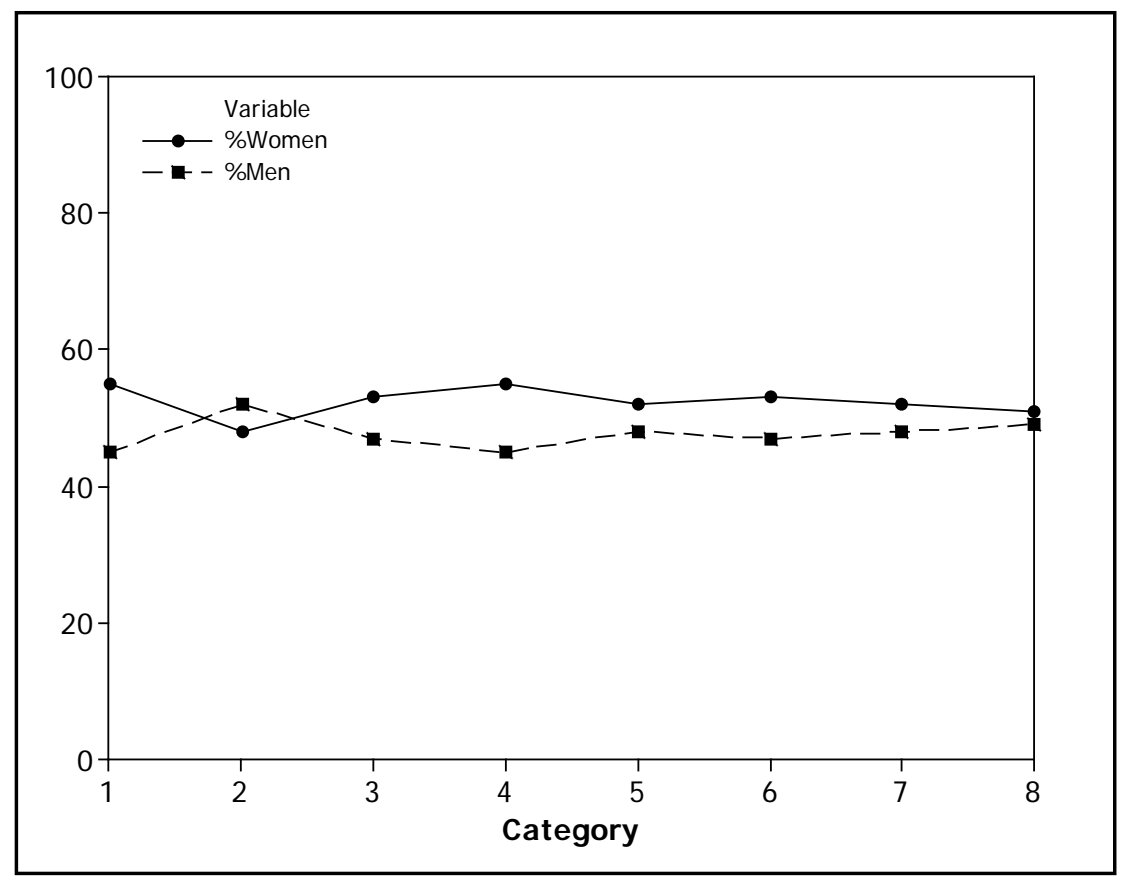

Figure 3. "Percentage of women and men by category. Example 3". Source: Own contribution

For a category in which the number of people is very low, the percentages of women and men can be non-significant. This may lead us to draw erroneous conclusions. In such situations it is also advisable to analyse the number of women and men in each category (Figure 4 shows an example in which these data have been plotted).

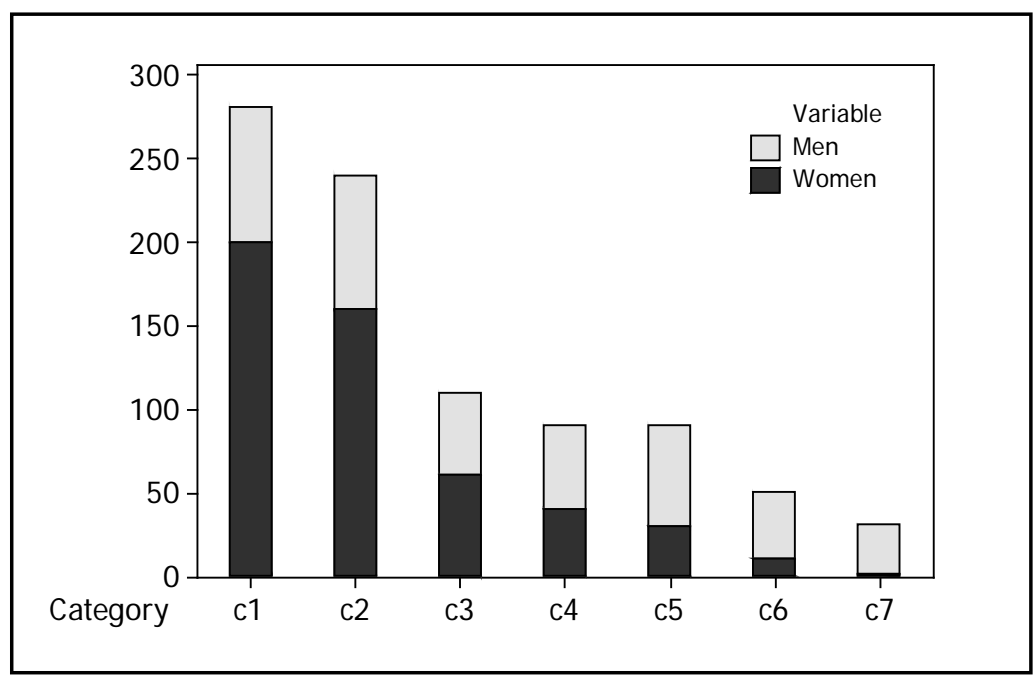

Figure 4. "Number of women and men by category". Source: Own contribution 
The distribution of women and men in different categories. Figures 5 and 6 illustrate two different examples:

o Example 1: shows a company in which women (regardless of whether there are only a few or a lot of women compared to the number of men) are found mainly in low categories. Men can be found mainly in the high categories. This could be due to the barriers and obstacles that prevent women from reaching high levels of responsibility (i.e., the glass ceiling effect).

o Example 2: shows a company in which women and men are distributed in a very similar way among categories, even though the company as a whole or some categories may not be genderbalanced. This is an ideal situation because it indicates that the chances of promotion do not depend on the gender.

Finally, if data were available, the evolution over time of the above aspects would allow us to check whether the development of the company in terms of the representation of women (one of the key aspects in equal opportunities between women and men) has improved during recent years or not.

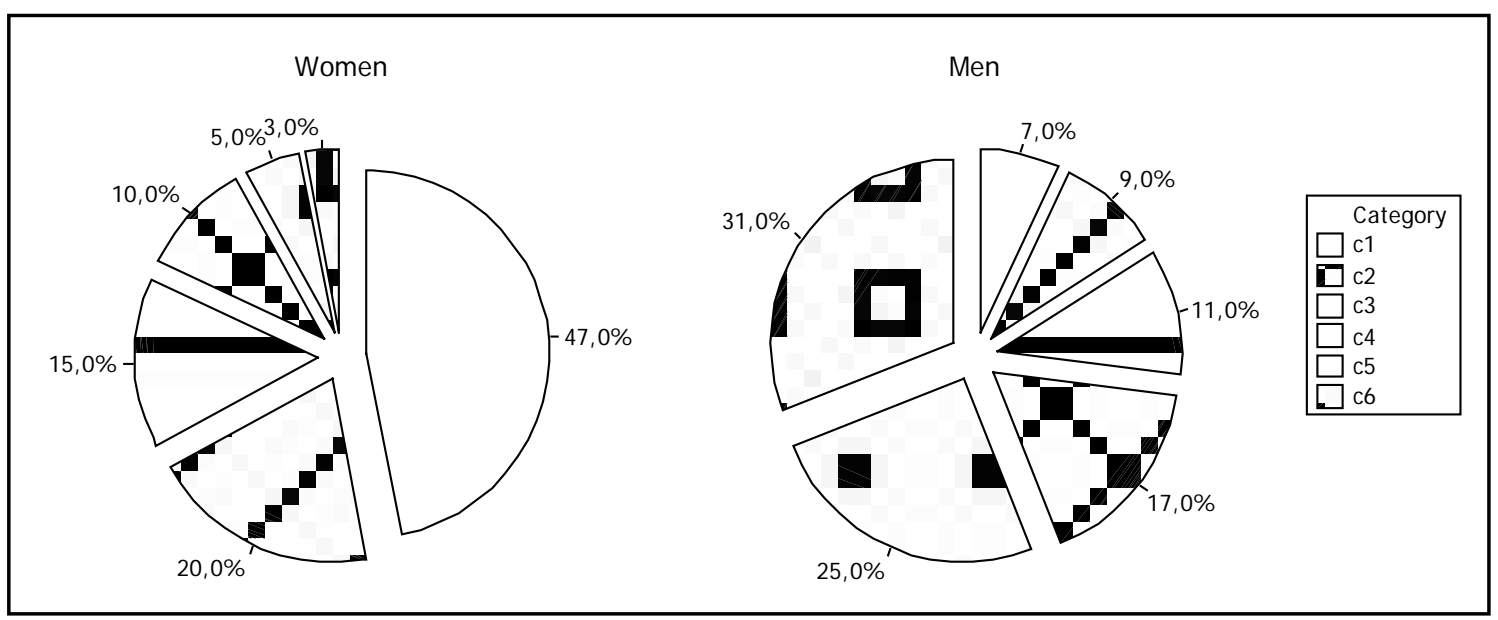

Figure 5. "Distribution of women and men among categories. Example 1". Source: Own contribution 


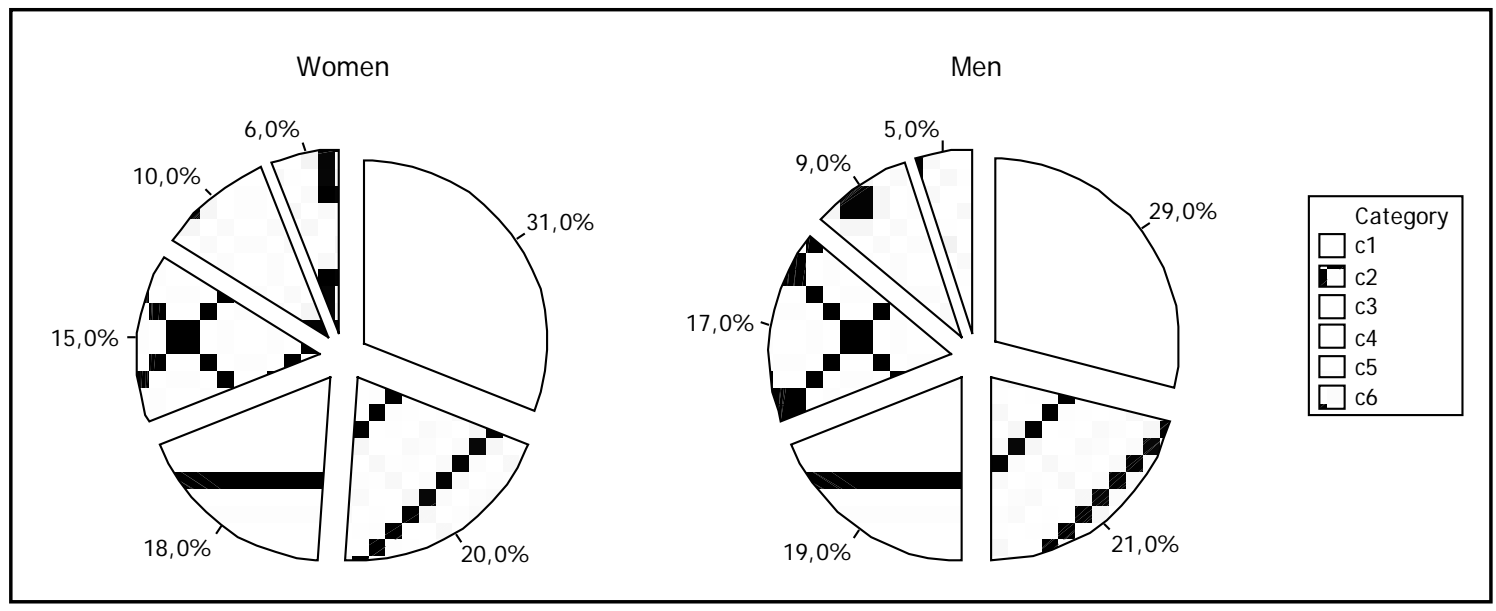

Figure 6. "Distribution of women and men among categories. Example 2". Source: Own contribution

\section{An indicator model for a complete diagnose}

We propose using an indicator model to carry out a complete assessment. This model is based on the study and improvement of indicators used in other areas of work (OIT, 2006; KILM, 2007; GRI, 2009; SA8000, 2009) and the creation of indicators that are capable of collecting and sizing the status of equal opportunities in organizations.

To perform a complete diagnose, the indicator model must cover all the policies and the external and internal processes of the company. For the purposes of the paper, the indicators of the model have been classified according to ten different fields which cover all the relevant policies and processes; these fields are described below.

\subsection{Fields covered by the model}

\section{Equal opportunities policy - gender mainstreaming}

This first field refers to the sensitivity and awareness of a company towards equal opportunities. The main aspects to evaluate are:

- The degree to which equal opportunities are integrated into the organisation's strategy and culture. The systematic incorporation of the gender perspective into the company's policies, decision-making procedures and activities (gender mainstreaming). 
- The staff's (at all levels) degree of commitment to and involvement in equal opportunities between women and men.

\section{Social responsibility}

A company is an organisation that is integrated in society. The behaviour of employees and relations with other companies (suppliers, customers, temporary employment agencies, etc.), administrations and institutions can help the company to contribute to achieving equal opportunities in society. This field evaluates:

- The company's contribution to equal opportunities in society (e.g., by means of setting society and other companies an example).

- The incorporation of the gender perspective into all projects (e.g., into the design of new products).

\section{$\underline{\text { Image and language }}$}

The image and language used at internal and external levels usually have a significant impact on equal opportunities (Garnsey \& Rees, 1996). The objective of this field is to assess:

- Whether the organisation makes women and their contribution to the company's results and success visible.

- The neutrality of the company's image and the language that is used at an internal level (documents, meetings, etc.) and at an external level (public functions, advertising, etc.).

\section{The representation of women}

As mentioned above, one of the main consequences of the lack of equal opportunities is the low representation of women in certain positions, categories or high levels of responsibility. There are basically three aspects that have to be checked:

- Whether the proportion of men and women in different departments, categories, management positions and on the board of directors is wellbalanced (neither women nor men should represent more than $60 \%$ or less than $40 \%$ ). 
- Whether the proportions of women and men are constant throughout the different categories (i.e., the proportion of women is not less in higher categories).

- Whether the distribution of women and men among the different categories is comparable.

\section{Career development}

This fifth field covers recruitment, selection, training, promotion and employee appraisals. The objectives are to verify whether equal opportunities are guaranteed in all of these human resources management processes. The following points should be checked:

- Whether there are equal opportunities in all steps of recruitment and promotion processes: criteria definition, tests, interviews and final decisions. To check whether the entire process is carried out with complete objectivity, equity and transparency and whether there are enough women on selection committees.

- Whether the organisation uses specific measures to favour and encourage the promotion of women to positions of responsibility or to the highest categories.

- Whether the organisation facilitates and promotes career development and skills improvement for all employees, guaranteeing equal opportunities in access to training courses and facilitating the participation of all staff members.

- Neutrality in employee appraisals.

\section{Pay policy}

The law (Directive 75/117 European Community ruling 1975 on equal pay in Europe and Equal Pay Act of 1963 in the case of the US) establishes that jobs of equal value must have equal pay. This principle is very difficult to guarantee because it is not easy to check whether two different jobs have the same value or not. As a result, the company may unwittingly cause salary discrimination. The following points are evaluated in this field: 
- Whether the company determines salaries by means of a neutral job evaluation procedure (i.e., a procedure that does not produce any negative effect on a certain group, women or men).

- Whether the assignment of jobs to categories and salary levels is adequate.

- Whether the payment policy is transparent.

- Whether there are signs of salary discrimination (i.e., if women's salaries are significantly lower than men's salaries).

\section{Harassment, sexist attitudes and the perception of discrimination}

The company should prevent sexual and moral harassment and sexist behaviour or discriminatory treatment at work. The objective of this field is to evaluate:

- Whether the company uses any measures to prevent, avoid and eliminate any sexist attitudes, discriminatory treatment or (sexual or moral) harassment.

- Whether sexist attitudes, discriminatory treatments or harassment of any type exist in the company.

- Whether employees feel that they are treated with fairness, dignity and respect.

\section{Labour conditions}

This field refers to labour conditions such as the kind of contract, working hours or dismissals. The aim is to check that:

- There is no gender discrimination in the type of contract or working hours of employees.

- There is no gender discrimination in dismissals.

\section{Work-life balance}

Many companies prefer not to employ women because they think that family burdens may prevent them from working as hard as men. There are several benefits of measures that help both women and men to combine work with family 
duties. First, men will start taking responsibility for family burdens. Second, if both women and men are responsible for children and household duties, companies will start recruiting and promoting women and men equally. Finally, if any position at work can be combined with personal and family life (and not only women take on family and household burdens), women will have the chance to occupy positions at the highest levels of responsibility. To summarize, this field evaluates:

- Whether employees of all categories and hierarchical levels have the opportunity to balance personal, family and work lives.

\section{Physical working conditions}

This last field aims to study measures for preventing risks at work, the ergonomics of the workplace, the distribution and arrangement of the space, and the adaptation of the workplace, the shared spaces and resources to the specific characteristics and needs of women (especially pregnant women). The following points should be evaluated:

- That resources and spaces are equally assigned and distributed.

- How the design of workplaces and shared resources and spaces takes into account the characteristics of both men and women.

\subsection{Indicator model}

A set of indicators has been defined for each of the ten fields. The model can be found in Table 1. It should be noted that the indicator model was designed for the present historical context, though it is flexible enough to be adapted to each age and situation.

\subsection{Gathering information and evaluating indicators}

The information source used for each indicator must be defined. Some indicators require quantitative information that can easily be found in databases. Other indicators may require document analysis (regulations, processes descriptions, layout plans, etc.), interviews with different people (managers, supervisors, people in charge of certain processes, etc.) or opinion polls (e.g., to evaluate the perception of discrimination). Such polls probably have to be designed ad hoc for each company. 


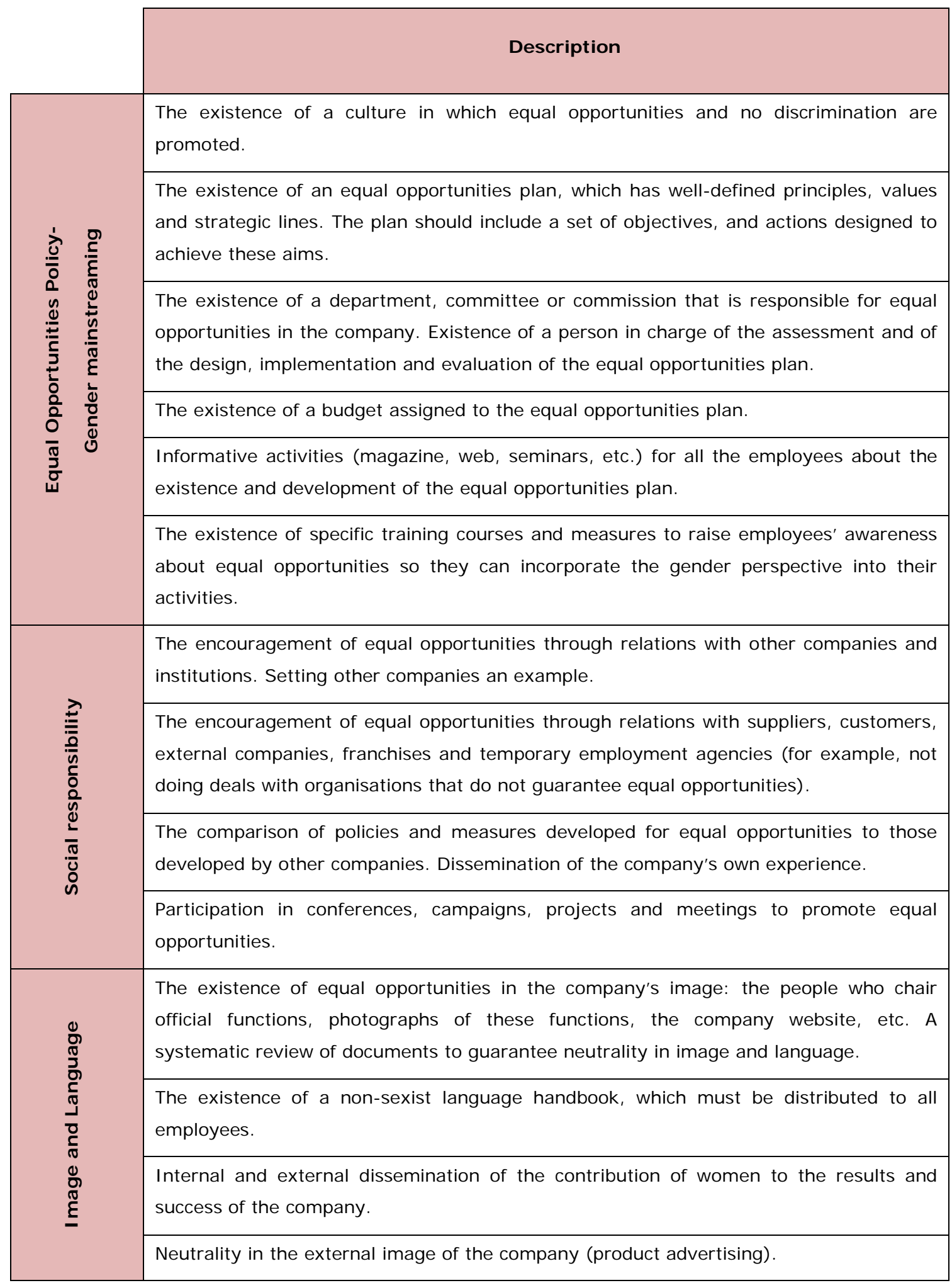

Table 1a. "Indicator model". Source: Own contribution 


\begin{tabular}{|c|c|}
\hline & Description \\
\hline \multirow{3}{*}{ 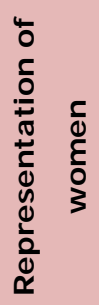 } & $\begin{array}{l}\text { Balance in the proportion of men and women in the different departments, categories, } \\
\text { management positions and on the board of directors. }\end{array}$ \\
\hline & $\begin{array}{l}\text { Continuity in the proportion of women and men in the different categories (i.e., the } \\
\text { proportion of women does not diminish in higher categories). }\end{array}$ \\
\hline & Equal distribution of women and men among categories. \\
\hline \multirow{8}{*}{ 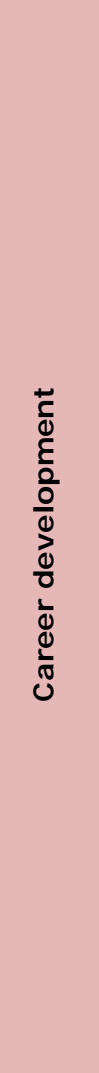 } & $\begin{array}{l}\text { The definition of neutral recruitment and selection techniques and tools. Neutrality of } \\
\text { application forms and the existence of a standard curriculum vitae to be filled in by the } \\
\text { candidates, which must guarantee neutrality and equal opportunities. }\end{array}$ \\
\hline & $\begin{array}{l}\text { The existence of an inventory of all jobs and their descriptions (tasks, functions, } \\
\text { responsibilities). The name of the jobs should be neutral and all the descriptions should } \\
\text { have the same format. }\end{array}$ \\
\hline & $\begin{array}{l}\text { The incorporation of the gender perspective into the human resources development } \\
\text { policy. The existence and dissemination of measures to promote women's career } \\
\text { development (leave for studies or exams, funding for studies). }\end{array}$ \\
\hline & $\begin{array}{l}\text { The existence of a performance evaluation system that guarantees objectivity, } \\
\text { neutrality and no discrimination. }\end{array}$ \\
\hline & $\begin{array}{l}\text { Equal numbers of women and men asking to attend training activities. Balance in the } \\
\text { number of women and men who are given permission to attend training activities. }\end{array}$ \\
\hline & $\begin{array}{l}\text { Equivalence between the proportion of female candidates for jobs and the proportion of } \\
\text { women getting jobs (for each type of contract, new workers should be distinguished } \\
\text { from internal promotion). }\end{array}$ \\
\hline & Equal numbers of women and men in charge of selection processes. \\
\hline & Existence of measures that encourage women's promotion. \\
\hline \multirow{2}{*}{ 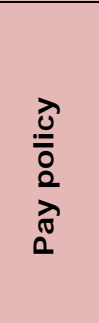 } & $\begin{array}{l}\text { Equal numbers of women and men at each pay level. Equivalence between the } \\
\text { distribution of women and men among pay levels. }\end{array}$ \\
\hline & $\begin{array}{l}\text { The assignment of jobs to categories based on a non-discriminatory job evaluation } \\
\text { procedure. The system should cover all relevant aspects of a job. The weight given to } \\
\text { each aspect should not lead to an undervaluation of jobs that are mainly occupied by a } \\
\text { specific sex. }\end{array}$ \\
\hline
\end{tabular}

Table 1b. "Indicator model". Source: Own contribution 


\begin{tabular}{|c|c|}
\hline & Description \\
\hline \multirow{3}{*}{ 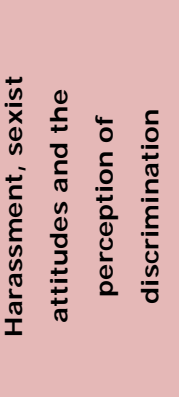 } & $\begin{array}{l}\text { The existence of a person, department, committee or commission in charge of designing } \\
\text { measures to prevent, detect and act in the face of harassment, sexist attitudes and } \\
\text { discriminatory treatment. }\end{array}$ \\
\hline & $\begin{array}{l}\text { The existence of measures to raise employees' awareness about harassment, sexist } \\
\text { attitudes and discriminatory treatment. }\end{array}$ \\
\hline & $\begin{array}{l}\text { No perception of gender discrimination (difficulty in being proposed for a promotion or a } \\
\text { top post, gender discrimination in relations with colleagues or supervisors). }\end{array}$ \\
\hline \multirow{4}{*}{ 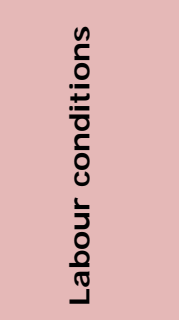 } & $\begin{array}{l}\text { Equality in the percentage of women and men with different types of contract and } \\
\text { working hours: part time, temporary, etc. }\end{array}$ \\
\hline & Balanced numbers of male and female dismissals. \\
\hline & The same number of women and men who have been on sick leave. \\
\hline & Neutrality in the criteria used to assign working hours to people. \\
\hline \multirow{3}{*}{ 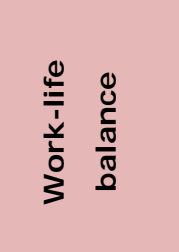 } & $\begin{array}{l}\text { The existence of measures for all employees that help to balance personal, family and } \\
\text { work lives. }\end{array}$ \\
\hline & The provision of facilities for asking for leave and the conditions of the return to work. \\
\hline & Meeting hours that help the balance between personal, family and working lives. \\
\hline \multirow{2}{*}{ 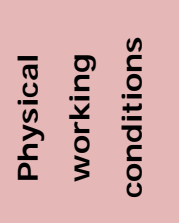 } & $\begin{array}{l}\text { Equality in conditions in the workplace and in the resources assigned to women and } \\
\text { men (office, space, privacy, lighting, windows, temperature, noise). }\end{array}$ \\
\hline & $\begin{array}{l}\text { Adaptation of the workplace and shared spaces (rooms, changing room, toilets, } \\
\text { showers, etc.) to both female and male characteristics. }\end{array}$ \\
\hline
\end{tabular}

Table 1c. "Indicator model". Source: Own contribution

The next step is information gathering. The company does not always have all the required information, so some indicators cannot be evaluated. Therefore, it is important to start analyzing the data even when the information gathering is not finished. An objective for the future may be to obtain the missing information.

Before starting to evaluate an indicator (once the required information is available), the ideal result and acceptable bounds for that indicator have to be defined. In other words, an assessment scale (that can be either quantitative or qualitative) must be defined. 
The set of indicators is quite heterogeneous. Therefore, to standardize the diagnosis, we propose evaluating all indicators according to a very simple and intuitive assessment scale based on three colours:

- Red: shows that the situation or factor evaluated by the indicator is not satisfactory and that the company should design and implement measures to improve this element appreciably. This colour can also be assigned to indicators that cannot be analyzed due to a lack of information.

- Amber: shows that the result is not satisfactory but that there are some measures in place, the company is making some effort, or intends to improve the situation.

- Green: shows that the factor evaluated by the indicator is satisfactory and that there is no need for specific measures.

The assessment of all indicators (except those for which no information is available) enables an overall equal opportunities diagnosis of the company to be completed. The next step is to design an action plan. The overall diagnosis can be summarized by means of a set of weak and strong points. The weak points will reflect objectives for the equal opportunities plan and identify those factors and situations that, with appropriate measures, could lead the company to deliver real equal opportunities. Note also that both the fast and complete diagnoses should be updated after implementing the equal opportunities plan, in order to evaluate its results and effectiveness.

\section{Conclusions}

Equal opportunities are now a matter that concerns all developed countries. Despite the great effort made by administrations and the progress of laws, gender discrimination still exists in family, social, cultural, political and economic spheres. In most companies, it is rare to find women in top level positions.

The path to equal opportunities is long and the only way to improve the situation is by means of appropriate equal opportunities plans. A diagnosis of the situation is an essential part of the process of designing and implementing an action plan. 
This paper proposes an innovative indicator model that can be used to carry out a complete diagnosis of the company's equal opportunities status. The diagnosis detects all the factors that could be corrected or improved by applying specific measures, leading the company to deliver real equal opportunities.

It is well known that top companies take care of their human resources. Of course, a situation in which all employees have the same opportunities to develop their professional career is highly advantageous to the company. First, employees' motivation and their commitment to work can be significantly improved. Second, the company will make good use of the potential and the ability of all members of the staff.

In addition, it is well known that there are some differences between women and men that they do not always approach problems in the same way. There is significant agreement on the benefits of diversity, but only a company with women at top levels can take advantage of these benefits.

Of course, the company should also think about its own corporative image. In today's society, a company in which only men are in charge of management is not well thought of by the public (i.e., potential clients).

All of the above reasons are enough to make companies think about diagnosing their equal opportunities situation and designing an action plan. The action plan will enable companies to benefit from the advantages that real equal opportunities between women and men can bring to a company.

The proposed indicator model has already been implemented in many companies in Spain. The results of the diagnose have allowed these companies designing their Equal Opportunities Action Plan. Of course, the indicator model is valid in the present legal and economic situation. Hence, a significant change in the situation would lead to an adaptation of the model.

In this moment the authors are working on plans for implementing equal opportunities in various companies and institutions, and the study of compliance with the measures described in some of the approved plans. We believe that the practice of laying on the instrument and to receive criticism from users can help to improve and define the model of indicators presented. 


\section{References}

European Commission (Employment, Social Affairs and Equal Opportunities). (2006a). Report on equality between women and men, 2006.

European Commission (Employment, Social Affairs and Equal Opportunities) (2006b). Women and men in decision-making. A question of balance.

Eurofund (European Foundation for the Improvement of Living and Working Conditions) (2002). Promoting gender equality in the workplace.

Garnsey, E., \& Rees, B. (1996). Discourse and enactment: Gender inequality in text and context. Human Relations, 49, 1041-1064.

Global Reporting Initiative (GRI) (2009). Home-page. Retrieved January, 2009, from http://www.globalreporting.org/Home

Gonäs, L. (2004). Gender Segregation and the European Employment Strategy: Levels and Divisions. European J ournal of Industrial Relations, 10, 139-59.

Key Indicators of the Labour Market Programme (KILM) (2007). General report (5a edition). Retrieved January, 2009, from http://www.ilo.org/public/english/employment/strat/kilm/

Kirton, G., \& Greene, A. M. (2005). Gender, Equality and Industrial Relations in the 'New Europe': An Introduction. European Journal of Industrial Relations, 11, 141149.

Knights, D., \& Richards, W. (2003). Sex discrimination in UK academia. Gender, Work and Organization, 10, 213-238.

OIT (2006). Igualdad de género y trabajo decente. Convenios y recomendaciones claves para la igualdad de género.

Rees, T. (1998). Mainstreaming Equality in the European Union. London: Routledge.

Rubery, J. (2002). Gender Mainstreaming and Gender Equality in the EU: The Impact of the EU Employment Strategy. Industrial Relations Journal, 33, 500522. 
Rubery, J., Grimshaw, D., Fagan, C., Figueiredo, H. \& Smith, M. (2003). Gender Equality still on the European Agenda: But for How Long? Industrial Relations Journal, 34, 477-497.

Social Accountability International 8000 (SA8000) (2009). General report.

Retrieved J anuary, 2009, from http://www.sa-intl.org/

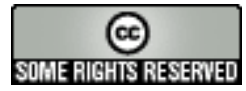

Article's contents are provided on a Attribution-Non Commercial 3.0 Creative commons license. Readers are allowed to copy, distribute and communicate article's contents, provided the author's and Journal of Industrial Engineering and Management's names are included. It must not be used for commercial purposes. To see the complete license contents, please visit http://creativecommons.org/licenses/by-nc/3.0/. 